\title{
Flavonoid chemistry and neuroprotection
}

\author{
Thomaz DV* \\ Faculty of Pharmacy, Federal University of Goiás, 240 street, Setor Leste Universitário, Goiânia - Goias State, Brazil
}

\begin{abstract}
This short commentary is intended to highlight the relevance of flavonoids in the therapeutics against neurodegenerative disorders. In this sense, this work briefly discuss the physicochemical and biological aspects which may be involved in the biological effects of these phytocomponents against oxidative stress in brain cells. Considering that literature abundantly describes the relevance of flavonoids in neuroprotection, care must be taken regarding their true clinical effectiveness, given the lack of information regarding their pharmacokinetic profiles and adequate pharmaceutical formulation.
\end{abstract}

\section{The basic chemistry of flavonoids}

Flavonoids are polyphenolic plant secondary metabolites which are biosynthesized from a polyketide chain and a phenylpyruvic moiety which may either come from shikimate or amino-acid metabolism [13]. These compounds possess remarkable physicochemical behavior due to their alternating $\pi$ bonds, what confers aromaticity and strong electroactivity [4]. Although the basic backbone of these compounds is widely produced in plant metabolism, polyphenols possess highly variable structure whose biosynthesis is dependent on several genetic and environmental factors [1,2]. The basic backbone of polyphenols is depicted in Figure 1 using flavanone Naringenin as example.

As previously seen in Figure 1 the alternating $\pi$ bonds of flavonoids allow the inductive effect of functional groups to be transmitted through the entire molecule, a principle known in medicinal chemistry as vinylogy $[5,6]$. This effect turns flavonoids into highly electroactive compounds, whose oxidation or reduction is thermodynamically feasible upon small physicochemical changes in the environment [7].

\section{The antioxidant capacity of flavonoids}

Many authors discussed the biological effects of this proneness of flavonoids to undergo redox reactions. In this sense, it is acknowledged that flavonoids and other polyphenols may "sacrifice" themselves in order to safeguard biological material $[8,9]$. This process is the very often quoted "antioxidant activity" and is based on the antioxidant compound (i.e. flavonoid) donating electrons to the unstable species (i.e. free radicals and other reactive oxygen species - ROS). However, the organisms do often possess highly effective antioxidant capabilities of their own, in the form of reductive enzymes such as peroxidases, superoxide dismutase (SOD) and others [10]. Given the capacity to donate and accept electrons, these enzymes are also prone to be preserved by the antioxidant capacity of flavonoids, what further enhances their appeal [10]. In this context, Figure 2 showcases how flavonoids are supposed to exert their antioxidant capacity.

As showcased in Figure 2, the oxidation of flavonoids is presumed to involve reversibility, as it was supported by many electroanalytical investigations [11-14]. In this sense, it can be implied that the restitution of the catechol after the formation of the benzoquinone is thermodynamically feasible, what could explain the higher radical
A<smiles>O=C1CC(c2ccc(O)cc2)Oc2cc(O)cc(O)c21</smiles>

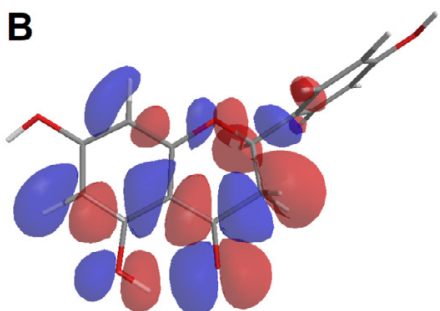

Figure 1. A. Chemical structure of flavonoid Naringenin. B. Graphical rendering of the first state of the highest occupied molecular orbital (HOMO n=0) according Hückel method [5]. Negative charges are colored in blue, while positive are colored red

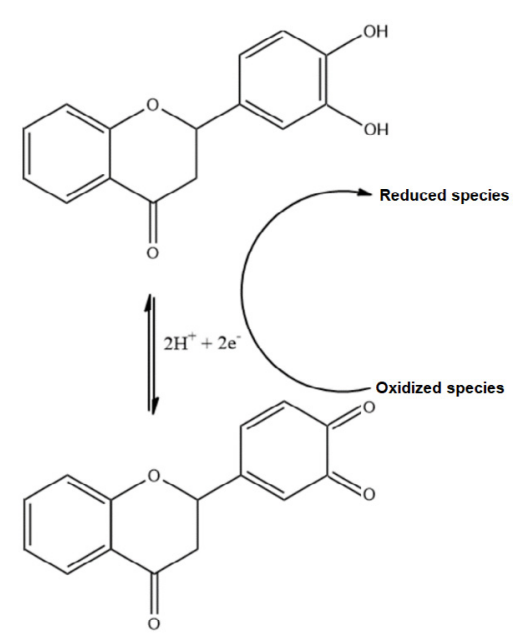

Figure 2. Proposed mechanism of a theoretical flavonoid redox reaction and its involvement in donating electrons to oxidized or unstable species and therefore reducing them

${ }^{*}$ Correspondence to: Douglas Vieira Thomaz, Faculty of Pharmacy, Federal University of Goiás, 240 street, Setor Leste Universitário, Goiânia - Goias State, Brazil, E-mail: douglasvthomaz@gmail.com

Key words: polyphenol pharmacokinetics, antioxidant capacity, neurodegenerative disorders, brain damage, pharmacognosy

Received: January 05, 2020; Accepted: January 17, 2020; Published: January 22, 2020 
scavenging of flavonoids in comparison to monophenols and also shed light on the biological implications of flavonoids as protective agents against oxidative stress.

\section{Neuroprotection and antioxidant capacity}

Oxidative stress is known to be involved in many neurodegenerative diseases, as free radicals such as ROS build up may lead to direct and diffuse cell damage $[10,11]$. There are many markers to evaluate the extent of oxidative damage, amongst them, malondialdehyde is one of the most used owing to its status as by product of lipid peroxidation [11]. Notwithstanding, peroxidases such as catalases (CAT) and reductive peptides and enzymes such as glutathione and SOD are also important biological markers to evaluate oxidative stress $[11,12]$. Although all cells are prone to undergo oxidative stress, those whose aerobic metabolism is remarkably high are more likely to showcase earlier the effects of this condition [15]. In this sense, oxidative stress may lead to neuronal damage, what can ultimately lead to neuron loss, being reflected as motor and cognitive impairment [11,12,16,17].

When neurodegenerative disorders are concerned, the first component in the pathogenesis of these diseases is the oxidative stress, albeit pathognomonic particularities are of upmost importance to differential diagnosis [18]. For instance, the term "neurodegenerative disorder" is considered an umbrella term, given that dementia, Alzheimer and many other diseases are based at least to some extent on neuron loss due to oxidative stress $[18,19]$.

Regarding the available treatments, most tackle the particularities of each disease as well as support therapy, hence restitution of the lost neuronal functions is still a controversial theme. Considering that oxidative stress is intimately linked to these diseases, long-term ingestion of exogenous antioxidants such as flavonoids might provide some protection $[11,12]$. In this sense, many authors tackled the effects of acute and chronic exposure to flavonoid-rich formulations in several experimental models, being transition metal salts such as $\mathrm{AlCl} 3$ or iron intoxication often used due to the electron accepting properties of these chemicals (which enhances ROS build up given the acidity of Lewis acids) as well as their capacity to interact with enzymes involved in neuron signalling $[11,12,20,21]$.

These investigations ultimately showcased that even acute exposure to flavonoids is beneficial to hinder neurodegeneration, however the high dose used in these experiments may turn continuous administration unpractical for life-long prophylaxis [22]. Moreover, function recovery and the extent of absorption and overall pharmacokinetics is still difficult to assess, given that the bioavailability of flavonoids and their feasibility to cross the blood-brain barrier is known to be highly variable according to the substituents in their chemical structure [23-25]. In this sense, more investigations could aid the comprehension of which pharmaceutical formulation should be optimal to properly administrate in a reproducible manner these phytocomponents in healthcare.

\section{Conclusion}

This short commentary was intended to highlight the relevance of flavonoids in the therapeutics against neurodegenerative disorders. It was observed that reports regarding the relevance of flavonoids in neuroprotection are plenty, however, care must be taken regarding their true effectiveness, given the lack of information regarding their pharmacokinetic profiles and adequate pharmaceutical formulation.

\section{Acknowledgement}

Author would like to thank CAPES, Brazil for the financial support.

\section{Conflict of interest}

Author declare that there is no conflict of interest.

\section{References}

1. Yang B, Liu H, Yang J, Gupta VK, Jiang Y (2018) New insights on bioactivities and biosynthesis of flavonoid glycosides. Trends in Food Science \& Technology 79: 116-124.

2. Xu W, Dubos C, Lepiniec L (2015) Transcriptional control of flavonoid biosynthesis by MYB-bHLH-WDR complexes. Trends in Plant Science 20: 176-185. [Crossref]

3. Nabavi SM, Šamec D, Tomczyk M, Milella L, Russo D, et al. (2020) Flavonoid biosynthetic pathways in plants: Versatile targets for metabolic engineering. Biotechnology Advances 38.

4. Heim KE, Tagliaferro AR, Bobilya DJ (2002) Flavonoid antioxidants: chemistry, metabolism and structure-activity relationships. The Journal of Nutritional Biochemistry 13: 572-584. [Crossref]

5. House JE (2018) Chapter 9 - The Hückel Molecular Orbital Method, Editor(s): J.E House, Fundamentals of Quantum Mechanics (Third Edition), Academic Press, 195-230.

6. Dan W, Dai J (2020) Recent developments of chalcones as potential antibacterial agents in medicinal chemistry. European Journal of Medicinal Chemistry 187: 111980. [Crossref]

7. Hendrickson HP, Kaufman AD, Lunte CE (1994) Electrochemistry of catecholcontaining flavonoids. Journal of Pharmaceutical and Biomedical Analysis 12: 325334. [Crossref]

8. Moreno EKG, Thomaz DV, Machado FB, Leite KCS, Rodrigues ESB, et al. (2019) Antioxidant Study and Electroanalytical Investigation of Selected Herbal Samples Used in Folk Medicine. International Journal of Electrochemical Science 14: 838-847.

9. Leite KCS, Garcia LF, Lobon GS, Thomaz DV, Moreno EKG, et al. (2018) Antioxidant activity evaluation of dried herbal extracts: an electroanalytical approach. Revista Brasileira de Farmacognosia-Brazilian 28: 325-332.

10. Thomaz DV, Peixoto LF, Oliveira TS, Fajemiore JO, Neri HFS, et al. (2018) Antioxidant and neuroprotective properties of Eugenia dysenterica leaves. Oxidative Medicine and Cellular Longevity 5: 1-9.

11. Oliveira TS, Thomaz DV, Neri HFS, Cerqueira LB, Garcia LF, et al. (2018) Neuroprotective effect of Camb. leaves is associated with anticholinesterase and antioxidant properties. Oxidative Medicine and Cellular Longevity 2018: 1-12.

12. Thomaz DV, Leite KCS, Moreno EKG, Garcia LF, Alecrim MF, et al. (2018) Electrochemical study of commercial black tea samples. International Journal of Electrochemical Science 13: 5433-5439.

13. Thomaz DV, Couto RO, Roberth AO, Oliveira LAR, Leite KCS, et al. (2018) Assessment of Noni (Morinda citrifolia L.) products authenticity by solid state voltammetry. International Journal of Electrochemical Science 13: 8983-8994.

14. Thomaz DV, Machado FB, Rodrigues ESB, Cunha CEP, Carvalho MF, et al. (2018) Assessment of antioxidant quality in Comercial Carqueja (Baccaris trimera) samples by electrochemical tools. Research Journal of Life Sciences, Bioinformatics, Pharmaceutical, and Chemical Sciences 4: 239-246.

15. Xu Z, Qian B (2020) Sevoflurane anesthesia-mediated oxidative stress and cognitive impairment in hippocampal neurons of old rats can be ameliorated by expression of brain derived neurotrophic factor. Neuroscience Letters 721: 134785. [Crossref]

16. Sun M, Shen X, Ma Y (2019) Rehmannioside A attenuates cognitive deficits in rats with vascular dementia (VD) through suppressing oxidative stress, inflammation and apoptosis. Biomedicine \& Pharmacotherapy 120: 109492. [Crossref]

17. Netto MB, Junior ANO, Goldim M, Mathias K, Fileti ME, et al. (2018) Oxidative stress and mitochondrial dysfunction contributes to postoperative cognitive dysfunction in elderly rats. Brain, Behavior, and Immunity 73: 661-669. [Crossref]

18. Arab A, Wojna-Pelczar A, Khairnar A, Szabó N, Ruda-Kucerova J (2018) Principles of diffusion kurtosis imaging and its role in early diagnosis of neurodegenerative disorders. Brain Research Bulletin 139: 91-98. [Crossref]

19. Vranová HP, Hényková E, Mareš J, Kaiserová M, Menšíková K, et al. (2016) Clusterin CSF levels in differential diagnosis of neurodegenerative disorders. Journal of the Neurological Sciences 361: 117-121. [Crossref] 
20. Bakhtiari M, Panahi Y, Ameli J, Darvishi B (2017) Protective effects of flavonoids against Alzheimer's disease-related neural dysfunctions. Biomedicine \& Pharmacotherapy 93: 218-229. [Crossref]

21. Ruan Q, Ruan J, Zhang W, Qian F, Yu Z (2018) Targeting NAD+ degradation: The therapeutic potential of flavonoids for Alzheimer's disease and cognitive frailty. Pharmacological Research 128: 345-358. [Crossref]

22. Rendeiro C, Rhodes JS, Spencer JPE (2015) The mechanisms of action of flavonoids in the brain: Direct versus indirect effects. Neurochemistry International 89: 126-139. [Crossref]
23. Youdim KA, Qaiser MZ, Begley DJ, Rice-Evans CA, Abbott NJ (2004) Flavonoid permeability across an in situ model of the blood-brain barrier. Free Radical Biology and Medicine 36: 592-604. [Crossref]

24. Youdim KA, Shukitt-Hale B, Joseph JA (2004) Flavonoids and the brain: interactions at the blood-brain barrier and their physiological effects on the central nervous system. Free Radical Biology and Medicine 37: 1683-1693. [Crossref]

25. Pogačnik L, Pirc K, Palmela I, Skrt M, Kim KS, et al. (2016) Potential for brain accessibility and analysis of stability of selected flavonoids in relation to neuroprotection in vitro. Brain Research 1651: 17-26. [Crossref]

Copyright: (C2020 Thomaz DV. This is an open-access article distributed under the terms of the Creative Commons Attribution License, which permits unrestricted use, distribution, and reproduction in any medium, provided the original author and source are credited. 